\title{
Interview with Jef Verschueren
}

\author{
Professor Emeritus at the Department of Linguistics, University of Antwerp
}

\section{Why Do You Regard the Field of Contrastive Pragmatics Interesting and Important?}

The importance of Contrastive Pragmatics seems self-evident to me and has both a theoretical dimension and a practical one. For the first dimension, a pragmatician should never lose sight of variability which is situated at different linguistic and communicative levels and can even extend to include an individual level of variability, as in the study of idiolects. There is variability within every language, so that intra-language variability is open to contrastive study, as in variational pragmatics. The most visible type of variability is what you find at the level of language systems, or what you briefly call "languages", and this is most commonly referred to when 'contrastive pragmatics' is talked about. Languages are abstractions but there is a certain level of stability which makes it possible to contrast systems, to be looked at as sedimented realization patterns of meaning potential.

From a practical point of view there are several fields for which Contrastive Pragmatics has direct use. There is language education, translation and interpreting, and intercultural communication. So, if one looks at language teaching, language learners need to learn to correlate expressions in language with context. For example, learners must be made aware of systems of politeness, where there are subtle differences with big consequences. You can have, for example, a simple form of teasing in American English instantiated by an utterance like "I thought you'd never ask" but when this phrase is translated, it may be received differently, lose its original innocent tone or sound very offensive. Also, grammatical patterns such as nominalizations can be very interesting. In almost all language systems you can package entire ideas into one construction, but languages differ in the possibilities they have available, and especially in how they treat them. All these differences need to be learned by language learners. The same applies for complex syntax; some languages prefer to juxtapose simpler sentences while others are more prone to packaging phrases to create an event complex. 
When it comes to translation and interpreting, Charles Fillmore in the early 198 os described the field that he was entering under the label of contrastive pragmatics by saying "I am going to describe a couple of pragmatic practices that don't translate well". That was his description of the field, and he focused on some minor elements and structures illustrating how languages function differently. For example, there is a traditional way in English of making suggestions in the form of negative-why questions, e.g. "Why don't we go to the movies tonight?". Again, this is a very traditional way of suggesting something in English but in other languages, when translated directly, it may come across as a kind of reproach or a question for explanation.

As to the field of intercultural communication, there are many endeavors that draw on the assumption that working with Contrastive Pragmatics could shed light into how communication differs interculturally. So, work by Blum Kulka, House and Kasper focused on how speech acts are realized in different languages, e.g. with emphasis on requests and apologies, which are interesting since they harbor face-saving risks, the former for the hearer, the latter for the speaker. Also, studies by Gumperz on communication styles or contextualization cues belong entirely in the field of Contrastive Pragmatics, even though he did not use the label. Here again, the point of interest was what happens in intercultural encounters.

However, a note of warning is useful here: in the field of intercultural communication it is not enough to only work with Contrastive Pragmatics, because that might imply that people are handled as if they are 'cultural dopes,' which is not the case. There are many adaptation processes that take place, and the situation is more complex than a simple juxtaposition of styles and practices. Still, Contrastive Pragmatics provides a lot of information about what happens.

\section{Where Do You Think the Field Needs to Move in the Future?}

It is difficult to predict developments, but it is possible to say something about the needs. For a long time, the main methodological question within Contrastive Pragmatics has been how to assess equivalence. There has been discussion about the need for Tertium comparationis to be able to compare two elements and decide on equivalence. One very important step would be to simply give up the idea of complete equivalence. Practicing translators have taken that step but from a theoretical point of view this needs to be fully admitted. The second step would be to systematically think about the variable realization of meaning potential, in terms of variability that emerges from the dynamic usage of forms for contextual indexing. There are different ways of realizing the same elementary aspects of meaning potential. All languages have ways of negating things, they do 
this in different ways, but the function is always available. The potential of negating may not be used in the same way or not as frequently in all languages. To give an example that I have used in the past: The Economist starts an article with the following sentence: It is easy to despair of the British Economy. This was translated into French as Il faut bien du courage pour ne pas désespérer de l'économie britannique (вт: one needs a lot of courage not to despair of the British economy). So, the French translator decides that a negation was needed instead of using a totally possible straightforward translation.

The question that emerges is then whether one can find patterns in this kind of variability.

One can start looking at how and to what extent languages differ in terms of how implicit meaning is anchored in what one says explicitly. So why is it that certain types of meaning need to be coded in one language but in others they can be inferred? In some languages, for example you use the same connective for disjunction and conjunction. In English, you need to code the distinction but in other languages the difference in meaning must be inferred from the contextual embedding of the utterances. One can also look at difference in the organization of interaction. Dingemanse and Enfield wrote on contrastive conversation analysis and looked at functionally important phenomena such as Other-initiated repair across of range of languages, making sure they kept the genre stable and comparable (specifically, very informal conversations between very close acquaintances).

If one looks at all these phenomena, the question is, as I already said, whether there are specific patterns underlying the cross-linguistic differences. Then looking into the future one can ask if we can dream about pragmatic typology. We are not ready for that yet, but a lot of groundwork can be done in that direction.

Of course, one cannot predict anything with certainty, also because the tools of investigation are changing. A lot can be done using computational techniques using large corpora and it is possible to imagine some forms of experimentation. Although I say that with some hesitation, as there is something self-contradictory about the notion of experimental pragmatics because pragmatics has to deal with actual language use and experimentation requires strict restrictions. But maybe smart tools can be developed that could help us arrive at something worthy of the label pragmatic typology, which may be a long-term outcome of work within contrastive pragmatics.

\author{
Interviewer: Themis P. Kaniklidou \\ Associate Professor in Translation and Communication, \\ Hellenic American University \\ Athens, Greece \\ tkaniklidou@hauniv.edu
}

